14,15

\title{
Механизм электролюминесценции в светоизлучающих полевых транзисторах на основе пленок нанокристаллов перовскита в матрице полупроводникового полимера
}

\author{
(C) О.П. Чикалова-Лузина ${ }^{1}$, В.М. Вяткин ${ }^{2}$, И.П. Щербаков ${ }^{1}$, А.Н. Алешин ${ }^{1,}$ \\ ${ }^{1}$ Физико-технический институт им. А.Ф. Иофрфе РАН, \\ Санкт-Петербург, Россия \\ ${ }^{2}$ Санкт-Петербургский государственный электротехнический университет „ЛЭТИ“, \\ Санкт-Петербург, Россия \\ ๆ E-mail:aleshin@transport.ioffe.ru
}

Поступила в Редакцию 6 апреля 2020 г.

В окончательной редации 6 апреля 2020 г.

Принята к публикации 9 апреля 2020 г.

Рассмотрены механизмы излучательной рекомбинации и электролюминесценции (ЭЛ) в структурах на основе пленок перовскитных нанокристаллов (HК) $\mathrm{CsPbBr}_{3}$ в матрице полупроводникового полимера MEH-PPV. Показано, что два механизма определяют интенсивность ЭЛ в светоизлучающих полевых транзисторах (СИ-ПТ) с активными слоями на основе пленок MEH-PPV : $\mathrm{CsPbBr}_{3}(\mathrm{HK})$ : рекомбинация заряженных носителей, инжектированных в полимерную матрицу и рекомбинация при интерфейсе полимер/НК перовскита. Результаты проведенных теоретических и экспериментальных исследований показали, что сверхлинейная зависимость интенсивности ЭЛ от уровня электрического возбуждения в СИ-ПТ на основе

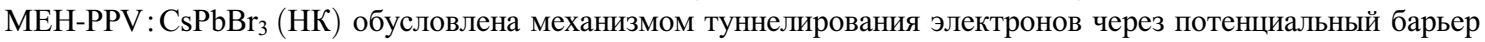
при электроде.

Ключевые слова: проводящие полимеры, нанокристаллы перовскитов, светоизлучающие полевые транзисторы, электролюминесценция.

DOI: $10.21883 /$ FTT.2020.08.49623.073

\section{1. Введение}

Металлоорганические галогенидные перовскиты представляют собой новые растворимые материалы с уникальными электрическими и оптическими свойствами [1]. Солнечные элементы на основе таких перовскитов демонстрируют эффективность преобразования солнечной энергии $\sim 25.2 \%$ (март 2020 г.) [2]. Эти материалы перспективны для применения в фотодетекторах [3], светоизлучающих диодах $[4,5]$, в полевых и светоизлучающих транзисторах (ПТ и СИ-ПТ), архитектура которых совмещает в себе как переключающие свойства ПТ, так и эмиссионные свойства светодиодов [6-8]. Однако, в виду того что металлоорганические галогенидные перовскиты недостаточно стабильны на воздухе, в последние годы интенсивно исследуются неорганические перовскиты - нанокристаллы (НК) галогенидов цезия $(\mathrm{CsPb} X, X=\mathrm{Cl}, \mathrm{Br}$ и I), обладающие более высокой стабильностью, способностью к перестройке оптических свойств, а также высоким квантовым выходом фото- и электролюминесценции (ФЛ и ЭЛ) [9].

Нами были разработаны композитные материалы, состоящие из неорганических перовскитных НК, внедренных в матрицу полупроводникового полимера, которые обладают свойствами, как проводящих полимеров, так и перовскитных НК. Были исследованы электрические и оптические свойства НК перовскитов $\left(\mathrm{CsPb}_{3}\right.$,
$\left.\mathrm{CsPbBr}_{3}\right)$, внедренных в матрицы полупроводниковых полимеров (PFO, MEH-PPV), а также ПТ и СИ-ПТ на их основе [10-13]. Было установлено, что при высоких уровнях оптического возбуждения основной вклад в сублинейную зависимость ФЛ от мощности оптического возбуждения вносит экситонная рекомбинация [12]. В то же время зависимость интегральной интенсивности ЭЛ от уровня электрического возбуждения в СИ-ПТ имела сверхлинейный характер. При этом подробный анализ механизмов ЭЛ в СИ-ПТ на основе пленок перовскитных НК в матрице полупроводниковых полимеров, таких как MEH-PPV : $\mathrm{CsPbB}_{3}(\mathrm{HK})$, до настоящего времени не проводился.

В работе проведен анализ экспериментальных данных для СИ-ПТ на основе MEH-PPV: $\mathrm{CsPbBr}_{3}(\mathrm{HK})$ и теоретически рассмотрены механизмы излучательной рекомбинации и ЭЛ в таких структурах. Показано, что в СИ-ПТ на основе пленок MEH-PPV:CsPbBr 3 (HK) наблюдающаяся сверхлинейная зависимость интегральной интенсивности ЭЛ обусловлена вероятностью туннелирования электронов через потенциальный барьер электрода.

\section{2. Объекты и методы исследования}

При приготовлении активного слоя рассматриваемых нами СИ-ПТ в качестве полимерной матрицы исполь- 
зован сопряженный полимер - (poly(2-methoxy-5(2ethylhexyloxy)-1,4-phenylenevinylene) (MEH-PPV) $\left(\mathrm{Cl}_{8} \mathrm{H}_{28} \mathrm{O}_{2}\right)_{n}$, с молекулярным весом $M_{w}=4-7 \cdot 10^{4}$ и шириной запрещенной зоны, $E_{g}=2.24 \mathrm{eV}$, полученный от Sigma Aldrich и применявшийся без дополнительной обработки. Нанокристаллы $\mathrm{Cspbr}_{3}$ были синтезированы идентично протоколу синтеза, описанному в [14]. НК $\mathrm{CsPbBr}_{3}$ имели кубическую форму с длиной грани $\sim 10 \mathrm{~nm}$ и $E_{g} \sim 2.7 \mathrm{eV}[11-13]$. На рис. $1, a-c$ показаны структуры молекул полимерной матрицы - MEH-PPV (a) и НК перовскита $\mathrm{CsPbBr}_{3}(b)$. СИ-ПТ были получены на основе композитных пленок MEH-PPV: $\mathrm{CsPbBr}_{3}(\mathrm{HK})$ и имели следующую структуру: $\quad n+\mathrm{Si} / \mathrm{SiO}_{2} / \mathrm{Au} / \mathrm{MEH}-\mathrm{PPV}: \mathrm{CsPbBr}_{3}(\mathrm{HK}) / \mathrm{Al}(\mathrm{Au})$ (рис. $1, c)$. В качестве диэлектрика был использован слой $\mathrm{SiO}_{2}$, толщиной $200 \mathrm{~nm}$, полученный термическим окислением $\mathrm{Si}$, на который термическим напылением наносились золотые $(\mathrm{Au})$ и алюминиевые $(\mathrm{Al})$ электроды, расстояние между которыми составляло $\sim 7 \mu \mathrm{m}$, а ширина $\sim 1 \mathrm{~mm}$. Порошок полимера MEH-PPV и $\mathrm{HK} \mathrm{CsPbBr}_{3}$ растворяли и диспергировали соответственно в толуоле. Растворы смешивали при различных относительных концентрациях MEH-PPV и $\mathrm{CsPbBr}_{3}$ НК и наносили на подложки методами полива или центрифугирования $(3000 \mathrm{rpm})$ с последующим высушиванием при $90^{\circ} \mathrm{C}$ в атмосфере азота в течение $15 \mathrm{~min}$. Толщина композитных пленок, нанесенных методом полива, составляла

$a$

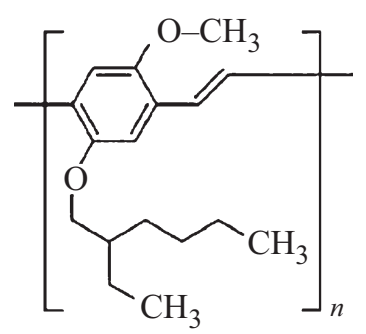

$b$
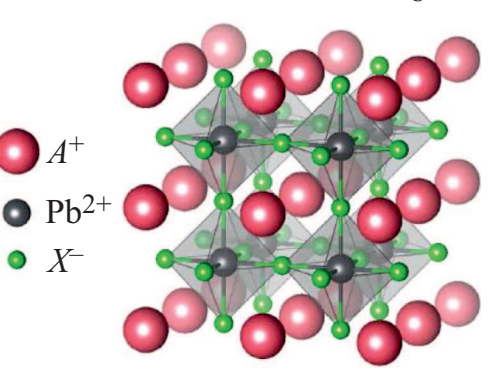

$c$

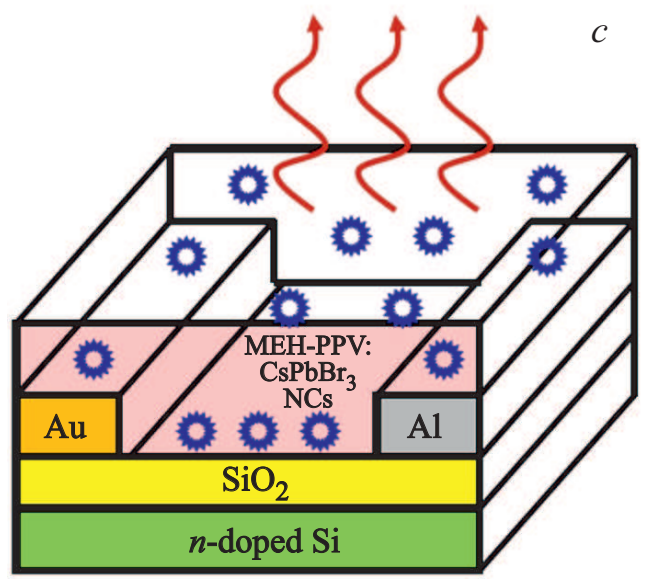

Рис. 1. Структура молекулы полимера MEH-PPV (a), HK $\mathrm{CsPbBr}_{3}(b)$ и СИ-ПТ на основе композитной пленки MEH-PPV : $\mathrm{CsPbBr}_{3}(\mathrm{HK})(c)$.

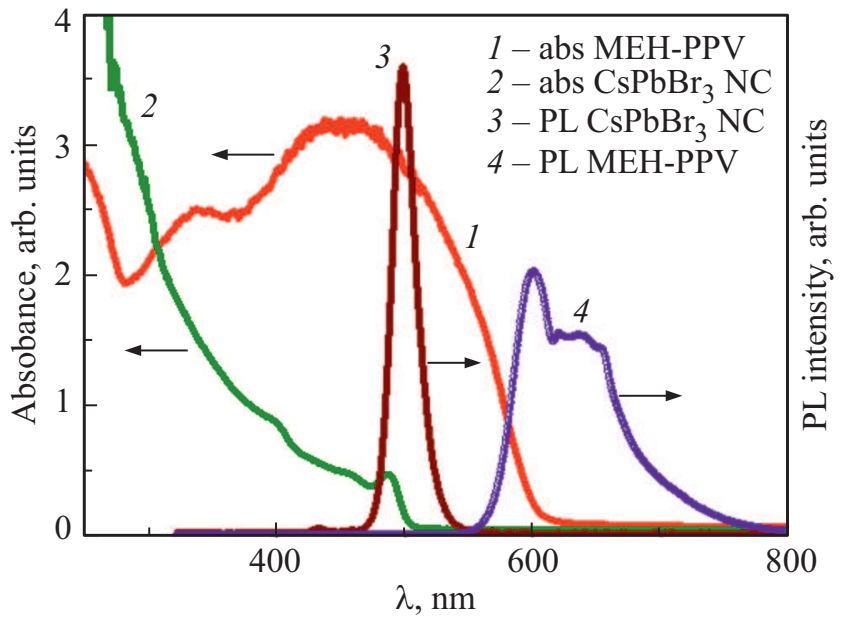

Рис. 2. Спектры поглощения пленок MEH-PРV (1), $\mathrm{CsPbBr}_{3}(\mathrm{HK})(2)$ и спектры ФЛ пленок $\mathrm{CsPbBr}_{3}(\mathrm{HK})$ (3), MEH-PPV (4) на кварцевых подложках.

$0.6 \mu \mathrm{m}$. Спектры поглощения пленок, осажденных на кварцевые подложки, регистрировали с использованием спектрометра Cary-50 (Varian). ФЛ пленок композитов возбуждалась УФ-светодиодом UVTOP280TO39HS с длиной волны излучения $285 \mathrm{~nm}$. Спектры ФЛ регистрировались высокочувствительным оптоволоконным спектрометром „AVANTES“ — AvaSpec-ULSi2048L-USB2 OEM, работающим в спектральном диапазоне 322-1100 nm. Типичные спектры поглощения исходных MEH-PPV (кривая 1), НK $\mathrm{CsPbBr}_{3}$ (кривая 2) и спектры ФЛ пленок $\mathrm{CsPBr}_{3}$ (кривая 3) и MEH-PPV (кривая 4) на кварцевых подложках показаны на рис. 2. Для возбуждения ЭЛ СИ-ПТ подавалось импульсное напряжение амплитудой от $+85 \mathrm{~V}$ до $-85 \mathrm{~V}$, с частотой $1 \mathrm{kHz}$, и длительностью $10 \mu$ s при помощи генератора Г3-56/1. Интегральная интенсивность ЭЛ СИ-ПТ измерялась с помощью фотоумножителя со спектральной чувствительностью в интервале $300-850 \mathrm{~nm}$. Вольт-амперные характеристики (BAX) СИ-ПТ измерялись в темноте при 290 К с использованием держателя оптического криостата optCRYO198 и автоматизированной измерительной системы на основе пикоамперметра Keithley 6487 и программируемого источника напряжения AKIP-1124. Напряжение на стоке-истоке и затворе ПТ варьировалось в пределах от -30 до $+30 \mathrm{~V}$ с переменным шагом. Контакты к ПТ выполнялись серебряной проволокой с использованием углеродных или серебряных паст.

\section{3. Результаты и обсуждение}

\section{1. Теоретическая модель}

На рис. 3, $a$ и $b$ представлены типичные выходные BAX СИ-ПТ на основе MEH-PPV:CsPbBr ${ }_{3}(\mathrm{HK})$ с соотношением компонентов $(1: 1)$ при отрицательных значениях $V_{\mathrm{G}}(a)$ и передаточные ВАХ того же СИ-ПТ 

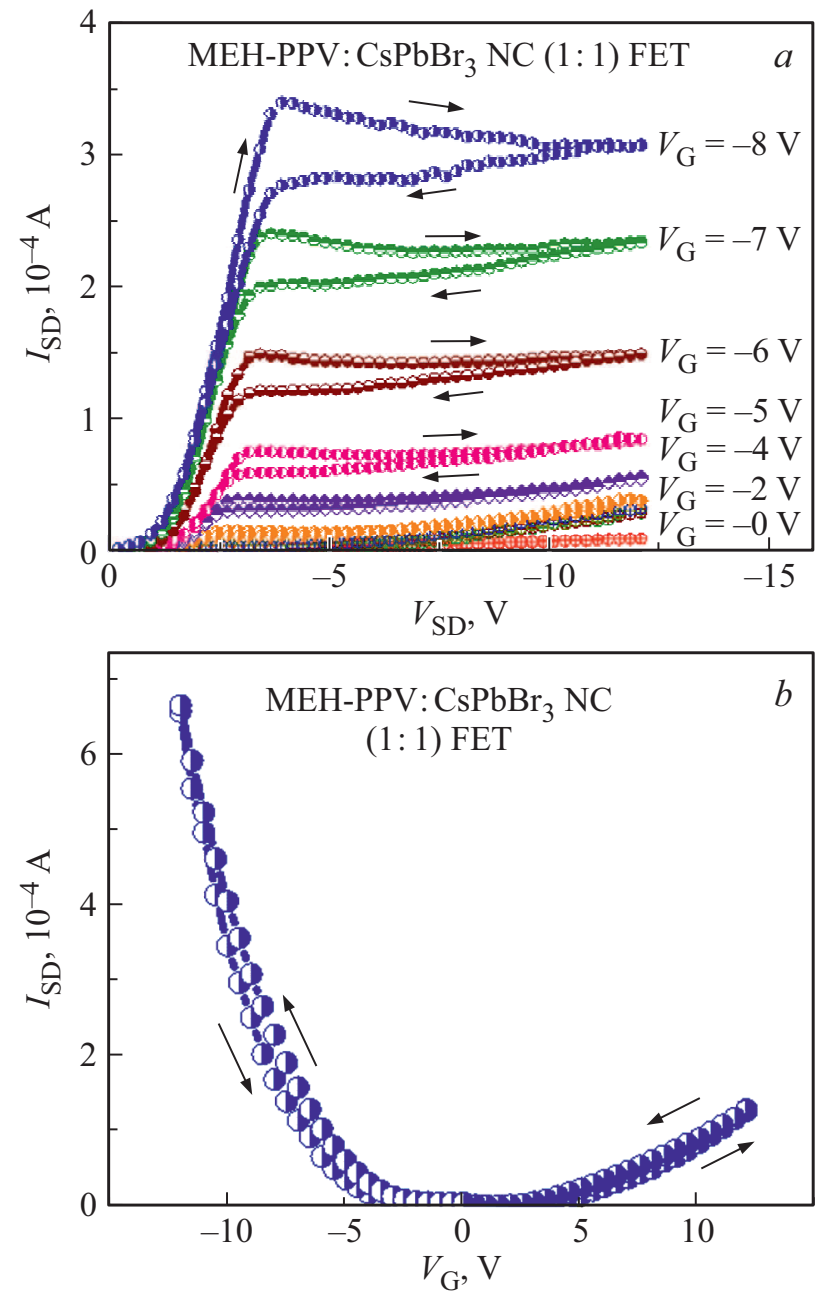

Рис. 3. a) - Выходные ВАХ MEH-PPV: $\mathrm{CsPbBr}_{3}(\mathrm{HK})$ $(1: 1)$ СИ-ПТ измеренные в темноте, при отрицательных значениях $\left.V_{\mathrm{G}} ; b\right)$ - Передаточные характеристики MEH-PPV : $\mathrm{CsPbBr}_{3}(\mathrm{HK})(1: 1)$ СИ-ПТ при $V_{\mathrm{SD}}=-4 \mathrm{~V}$ измеренные в темноте при $290 \mathrm{~K}$.

при $V_{\mathrm{SD}}=-4 \mathrm{~V}$, измеренные в темноте. Из рис. 3 видно, что выходные и передаточные ВАХ СИ-ПТ имеют вид, характерный для преобладающего дырочного транспорта [12].

В качестве механизма, описывающего транспорт в рассматриваемых СИ-ПТ, нами была использована модель, предложенная в работе [15]. Согласно этой модели, дырочный ток течет к стоку, который имеет отрицательный потенциал по отношению к истоку, при этом смещение на затворе вызывает аккумуляцию дырок в канале полевого транзистора. На рис. 4 схематически изображена диаграмма энергетических уровней, иллюстрирующая инжекцию электронов и дырок в органическую матрицу MEH-PPV. Электроны, инжектируемые в результате туннелирования на LUMO уровень полимера, имеют высокую вероятность захвата положительно заряженными молекулами органической матрицы, что приводит к образованию экситонов, которые далее излучательно рекомбинируют. Для простоты в этой модели рассматривается только собственная молекулярная эффективность излучения света, а влияние примесных и межмолекулярных излучательных процессов учитывается введением подгоночного параметра $Q_{L}$. Схематическое изображение барьера между металлическим электродом и полимерной матрицей представлено на рис. 5. Барьер имеет треугольную форму высоты $H$, равной разности уровней LUMO-HOMO полимера MEH-PPV. Ширина барьера $W$ обратно пропорциональна напряжению между стоком и истоком $V_{\mathrm{SD}}$ и прямо пропорциональна $L$-протяженности области падения потенциала. Феноменологический параметр $L$ зависит от природы интерфейса металл-органическая матрица. Он может быть определен из экспериментальных данных, а именно, из выходных ЭЛ характеристик. В нашей работе для $L$ принимались значения от 3 до $15 \mathrm{~nm}$.

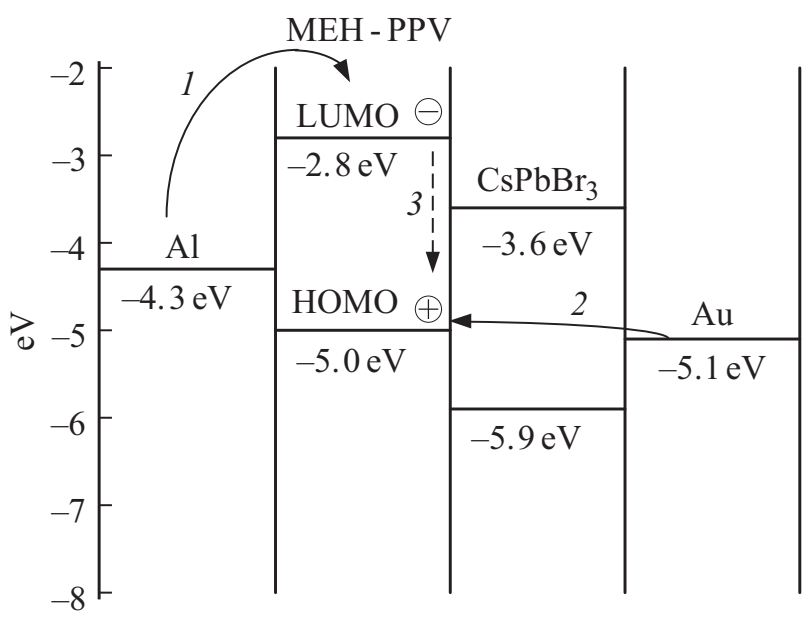

Рис. 4. Диаграмма энергетических уровней, иллюстрирующая инжекцию электронов и дырок в органическую матрицу MEH-PPV: (1) - инжекция электронов (туннелирование); (2) - инжекция дырок; (3) - рекомбинация электрондырочных пар.

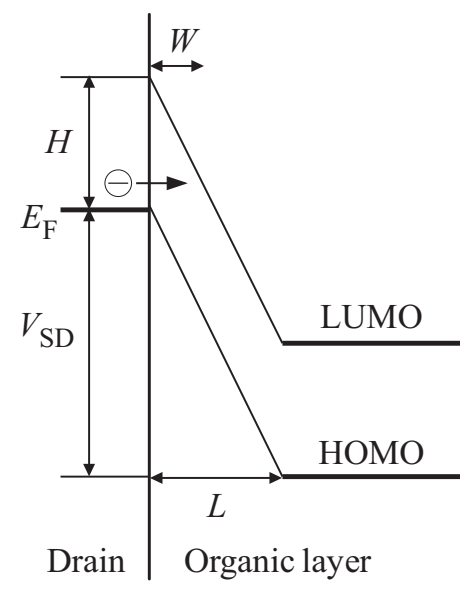

Рис. 5. Схематическое изображение барьера между металлическим электродом и полимерной матрицей. 
Аналитические уравнения (1) и (2) позволяют оценить число электронно-дырочных пар, образованных в канале $\left(N_{e-h}\right)$, дырочный ток $\left(I_{\mathrm{D}}\right)$, вероятность туннелирования электронов $\left(P_{e}\right)$ и число эмитированных фотонов $\left(N_{P h s}\right)$

$$
N_{e-h}=\frac{I_{\mathrm{D}}\left(V_{\mathrm{SD}}, V_{\mathrm{GS}}\right)}{e} P_{e}\left(V_{\mathrm{SD}}\right)
$$

где $I_{\mathrm{D}}$ и $P_{e}$ определяются следующими уравнениями [15]:

$$
\begin{gathered}
I_{\mathrm{D}}=\frac{W_{C} \mu_{\mathrm{h}} C_{0 x}}{L_{\mathrm{C}}}\left[\left(V_{\mathrm{Gs}}-V_{\mathrm{Th}}\right) V_{\mathrm{SD}}-\frac{1}{2} V_{\mathrm{SD}}^{2}\right], \quad V_{\mathrm{SD}}<V_{\mathrm{GS}}-V_{\mathrm{Th}}, \\
I_{\mathrm{D}}=\frac{W_{C} \mu_{\mathrm{h}} C_{0 x}}{2 L_{\mathrm{C}}}\left(V_{\mathrm{GS}}-V_{\mathrm{Th}}\right)^{2}, \quad V_{\mathrm{SD}} \geq V_{\mathrm{GS}}-V_{\mathrm{Th}} \\
P_{e}\left(V_{\mathrm{SD}}\right) \cong 4 \sqrt{\left(1-\frac{H}{e V_{\mathrm{SD}}}\right) \frac{H}{e V_{\mathrm{SD}}}} \exp \left(-\frac{4}{3} \frac{W}{\hbar} \sqrt{2 m H}\right), \\
H=E_{\mathrm{LUMO}}-E_{\mathrm{HOMO}}, \\
W=H \frac{L}{e V_{\mathrm{SD}}}, \\
N_{P h s}=Q_{L} N_{e-h}\left(V_{\mathrm{SD}}, V_{\mathrm{GS}}\right) .
\end{gathered}
$$

$W_{C}, L_{C}$ и $\mu_{h}$ - ширина и длина канала, а также подвижность дырок соответственно, $C_{0 x}-$ емкость на единицу площади $\mathrm{SiO}_{2} . V_{\mathrm{SD}}, V_{\mathrm{GS}}-$ напряжение на стоке-истоке и на затворе, соответственно, $V_{\mathrm{Th}}-$ пороговое напряжение, соответствующее началу режима насыщения.

Анализ механизма ЭЛ в СИ-ПТ на основе пленок перовскитных НК в матрице полимера МЕН-PPV требует учета влияния НК перовскита на процессы, связанные с ЭЛ. Рассмотрим процессы, которые могут влиять на интегральную интенсивность ЭЛ СИ-ПТ. При интерфейсе полимерная матрица/НК электрон, протуннелировавший из электрода на LUMO уровень полимера, может быть инжектирован в зону проводимости НК и затем подвергнуться рекомбинации с дыркой в полимерной матрице при интерфейсе $[16,17]$, как показано на рис. 6. Это приводит к излучению света в ИК-области (на длине волны $890 \mathrm{~nm}$ ), что не дает вклада в интегральную интенсивность в спектральной области ЭЛ матрицы MEH-PPV. Поскольку часть инжектированных в матрицу электронов в этом процессе уходит из матрицы, рассмотренная рекомбинация приводит к уменьшению интегральной интенсивности ЭЛ матрицы. Безызлучательная релаксация электронов, захваченных ловушками на поверхности НК, также приводит к уменьшению интегральной интенсивности ЭЛ. Инжекция дырок из полимерной матрицы в валентную зону НК маловероятна из-за наличия барьера (рис. 4). Следовательно, образование возбужденных состояний в НК (электрондырочные пары) мало вероятно и рекомбинация зоназона в НК менее вероятна, чем рекомбинация электрона в НК и дырки в матрице, где не требуется преодоление барьера (рис. 6). Так же маловероятен безызлучательный

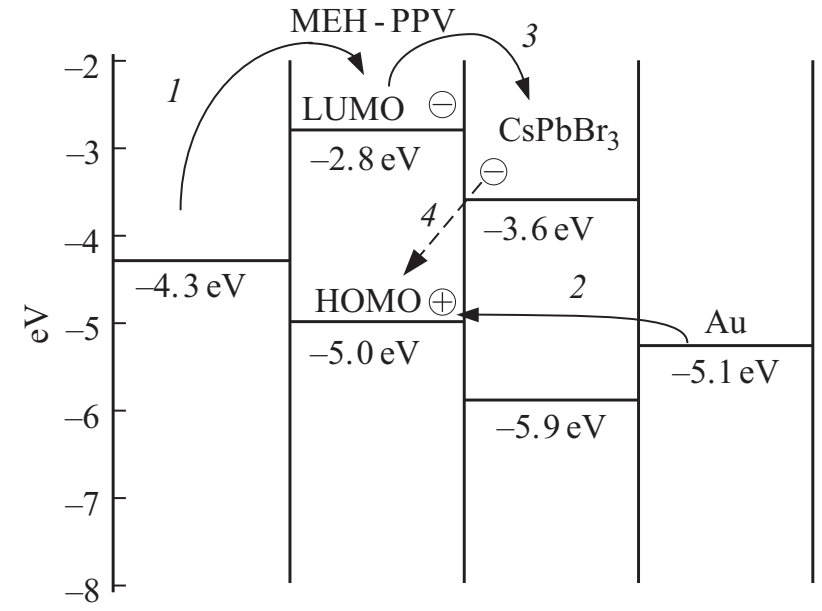

Рис. 6. Схема рекомбинации носителей при интерфейсе НК перовскита/матрица полимера: (1) - инжекция электронов из электрода на LUMO матрицы MEH-PPV; (2) - инжекция дырок в матрицу; (3) - инжекция электрона из матрицы в зону проводимости НК перовскита; (4) - интерфейсная электрон-дырочная рекомбинация.

перенос энергии возбуждения от НК к матрице по механизму Ферстера, несмотря на то, что выполняется необходимое условие для этого механизма - перекрытие спектра ФЛ НК со спектром поглощения матрицы MEH-PPV (рис. 2, кривые 3 и 1). Безызлучательный перенос энергии от матрицы к НК тоже не возможен, поскольку спектр ФЛ матрицы не перекрывается со спектром поглощения НК (рис. 2, кривые 4 и 2). Таким образом, в интегральной интенсивности ЭЛ исследованного нанокомпозита $\mathrm{MEH}-\mathrm{PPV}: \mathrm{CsPbB}_{3}(\mathrm{HK})$ вклад механизма Ферстера не существенен. Можно полагать, что два механизма определяют интенсивность ЭЛ в СИ-ПТ на основе пленок MEH-PPV : $\mathrm{CsPbBr}_{3}(\mathrm{HK})$ : peкомбинация заряженных носителей, инжектированных в полимерную матрицу, и рекомбинация при интерфейсе матрица полимера/НК перовскита.

\section{2. Эксперимент и сравнение с теоретической моделью}

В рамках изложенной выше модели были выполнены расчеты и построены зависимости $I_{\mathrm{D}}\left(V_{\mathrm{SD}}, V_{\mathrm{GS}}\right)$ (при $\left.V_{\mathrm{GS}}=-30 \mathrm{~V} ;-20 \mathrm{~V} ; V_{\mathrm{SD}}=0-30 \mathrm{~V}\right)$ и зависимости интегральной интенсивности ЭЛ от $V_{\mathrm{SD}}$ и $V_{\mathrm{GS}}$ для параметров СИ-ПТ на основе MEH-PPV (100\%), указанных в работе [12] для $\left(W_{C}=1 \mathrm{~mm}, L_{C}=7 \mu \mathrm{m}\right.$, $\left.\mu_{\mathrm{h}}=2-5 \mathrm{~cm}^{2} / \mathrm{Vs}, V_{\mathrm{Th}}=-1 \mathrm{~V}\right)$. При выполнении расчетов была введена поправка, учитывающая собственный объем НК перовскитов в нанокомпозитной пленке с использованием результатов работы [13]. На рис. 7 и 8 приведены графики зависимостей $I_{\mathrm{D}}\left(V_{\mathrm{SD}}, V_{\mathrm{GS}}\right)$, а также $N_{e-h}\left(V_{\mathrm{SD}}, V_{\mathrm{GS}}\right)$, для СИ-ПТ на основе $\mathrm{MEH}-\mathrm{PPV}(100 \%)$. Как видно из рис. 8, число электронно-дырочных пар, 
образованных в канале $\left(N_{e-h}\right)$ для чистого MEH-PPV, a, следовательно, и интегральная интенсивность ЭЛ, возрастает сверхлинейно при возрастании $V_{\mathrm{SD}}$ от $-10 \mathrm{~V}$ до $-30 \mathrm{~V}$ и стремится к насыщению при высоких $V_{\mathrm{SD}}$. Этот вывод находится в качественном согласии с полученными нами зависимостями интегральной интенсивности ЭЛ при приложении импульсного $V_{\mathrm{SD}}$ для СИ-ПТ на основе пленок MEH-PPV, приведенными на рис. 9 [12].

Следует отметить, что экспериментальные данные показывают большее уменьшение интегральной интен-

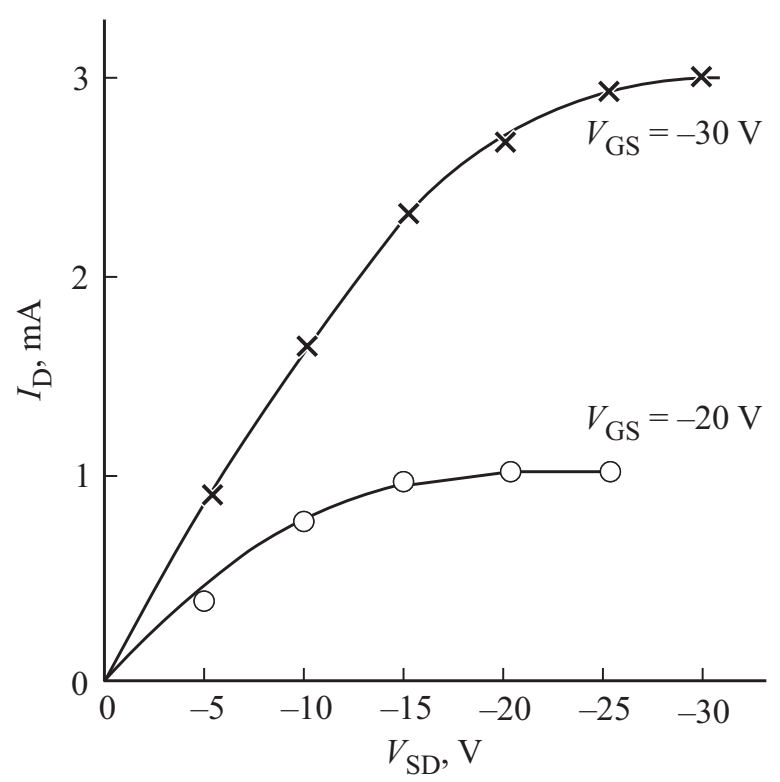

Рис. 7. Зависимости $I_{\mathrm{D}}$ от $V_{\mathrm{SD}}$ и $V_{\mathrm{GS}}$ для MEH-PPV (100\%).

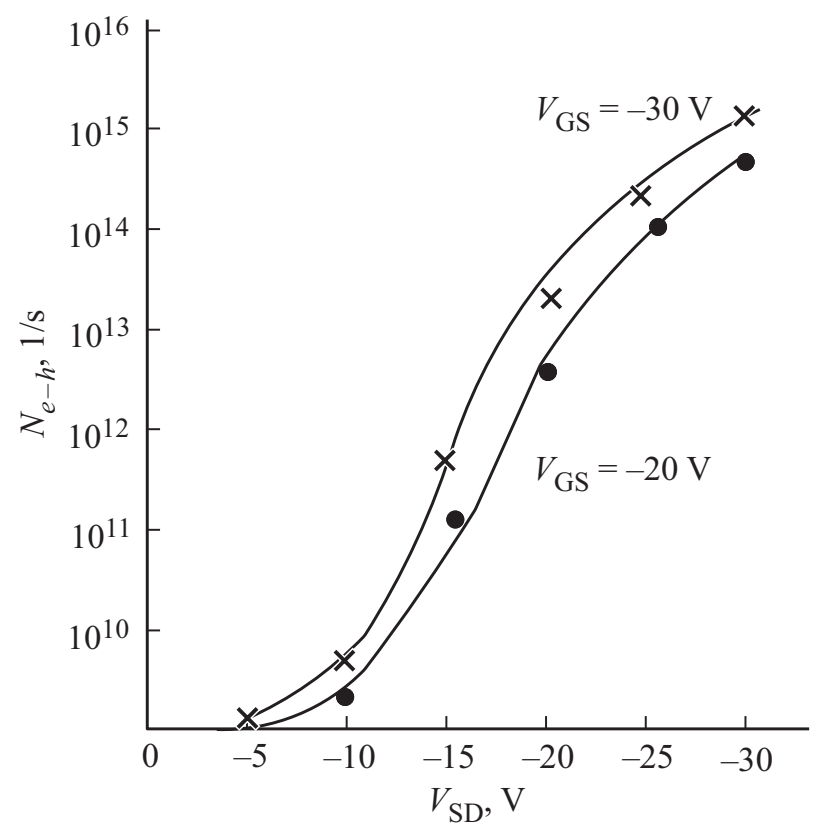

Рис. 8. Зависимость числа электронно-дырочных пар, образованных в канале, $N_{e-h}$ от $V_{\mathrm{SD}}$ для MEH-PPV (возрастает сверхлинейно при возрастании $\left.V_{\mathrm{SD}}\right)$.

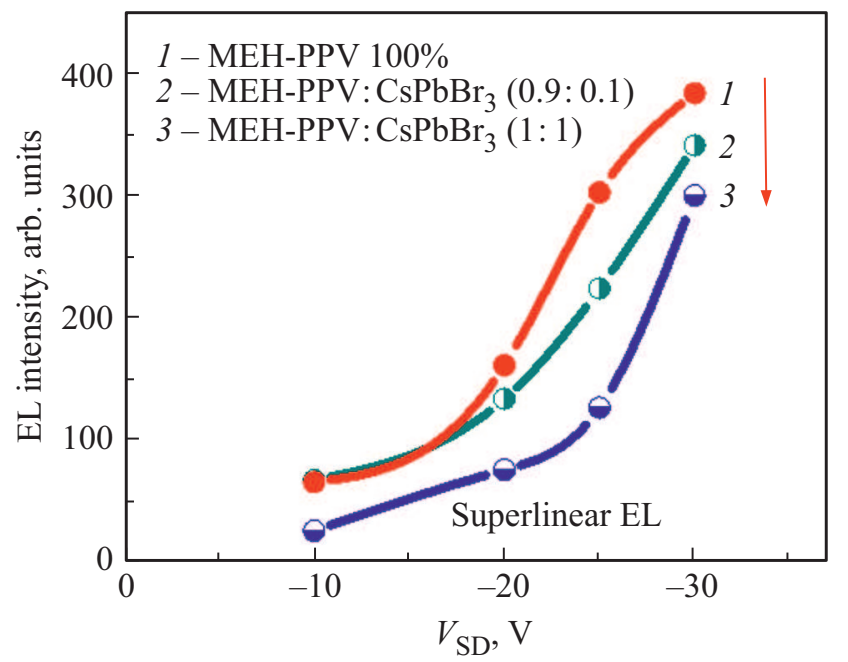

Рис. 9. Интенсивность интегральной ЭЛ при приложении импульсного $V_{\mathrm{SD}}$ для СИ-ПТ на основе пленок: 1) MEH-PPV (100\%); 2) MEH-PPV:CsPbBr 3 (HK) (0.9:0.1); 3) MEH-PPV: $\mathrm{CsPbBr}_{3}(\mathrm{HK})(1: 1)$.

сивности ЭЛ при введении НК перовскита в матрицу полимера MEH-PPV по сравнению с тем, что дает теоретический расчет, учитывающий уменьшение объема матрицы. К дополнительному уменьшению интегральной интенсивности ЭЛ с увеличением концентрации НК перовскитов приводит, как уже отмечалось, рекомбинация при интерфейсе электрона, захваченного НК, и дырки в матрице, которая не дает вклада в интенсивность в области ЭЛ полимерной матрицы (рис. 9).

Наблюдаемые некоторые различия экспериментальных и теоретических данных для интегральной интенсивности ЭЛ композитов, по-видимому, связаны с уменьшением объема матрицы при введении НК и рекомбинацией электронов и дырок на интерфейсе перовскитный НК/полимерная матрица. Количественный анализ интерфейсной рекомбинации будет предметом нашей будущей работы.

\section{4. Заключение}

Рассмотрены механизмы излучательной рекомбинации и ЭЛ в структурах на основе перовскитных НК в матрице полупроводникового полимера. Показано, что два механизма определяют интенсивность ЭЛ в СИ-ПТ на основе пленок MEH-PPV: $\mathrm{CsPbBr}_{3}(\mathrm{HK})$ : рекомбинация заряженных носителей, инжектированных в полимерную матрицу и рекомбинация при интерфейсе полимер/НК перовскита. Выполненный расчет показал, что сверхлинейная зависимость интегральной интенсивости ЭЛ от уровня электрического возбуждения обусловлена процессом туннелирования электронов через потенциальный барьер при электроде. 


\section{Благодарности}

Авторы благодарны Л.Б. Матюшкину за синтез НК перовскитов и И.Н. Трапезниковой за помощь в измерении спектров поглощения.

\section{Конфликт интересов}

Авторы заявляют, что у них нет конфликта интересов.

\section{Список литературы}

[1] F. Deschler, M. Price, S. Pathak, L.E. Klintberg, D-D. Jarausch, R. Higler, S. Hüttner, T. Leijtens, S.D. Stranks, H.J. Snaith, M. Atatüre, R.T. Phillips, R.H. Friend. J. Phys. Chem. Lett. 5, 1421 (2014).

[2] National Renewable Energy Laboratory, Best Research Cell Efficiencies, www.nrel.gov/ncpv/images/efficiency_chart.jpg; accessed: March 2020

[3] S. Ahmad, P.K. Kanaujia, H.J. Beeson, A. Abate, F. Deschler, D. Credgington, U. Steiner, G.V. Prakash, J.J. Baumberg. ACS Appl Mater. Interfaces 7, 25227 (2015).

[4] Z.-K. Tan, R.S. Moghaddam, M.L. Lai, P. Docampo, R. Higler, F. Deschler, M. Price, A. Sadhanala, L.M. Pazos, D. Credgington, F. Hanusch, T. Bein, H.J. Snaith, R.H. Friend. Nature Nano 9, 687 (2014).

[5] Y.-H. Kim, H. Cho, J.H. Heo, T.-S. Kim, N. Myoung, C.-L. Lee, S.H. Im, T.-W. Lee. Adv. Mater. 27, 1248 (2015).

[6] T. Matsushima, S. Hwang, A.S.D. Sandanayaka, C. Qin, S. Terakawa, T.U. Fujihara, M. Yahiro, C. Adachi. Adv. Mater. 28, 10275 (2016).

[7] S.P. Senanayak, B. Yang, T.H. Thomas, N. Giesbrecht, W. Huang, E. Gann, B. Nair, K. Goedel, S. Guha, X. Moya, C.R. McNeill, P. Docampo, A. Sadhanala, R.H. Friend, H. Sirringhaus. Sci. Adv. 3, e1601935 (2017).

[8] X.Y. Chin, D. Cortecchia, J. Yin, A. Bruno, C. Soci. Nature Commun. 6, 7383 (2015).

[9] H.-C. Wang, Z. Bao, H.-Yu. Tsai, A.-C. Tang, R.-S. Liu. Small 14, 1702433 (2018).

[10] A.N. Aleshin, I.P. Shcherbakov, E.V. Gushchina, L.B. Matyushkin, V.A. Moshnikov. Organ. Electron. 50, 213 (2017).

[11] А.Н. Алешин, И.П. Щербаков, Д.А. Кириленко, Л.Б. Матюшкин, В.А. Мошников. ФТТ 61, 388 (2019).

[12] A.N. Aleshin, I.P. Shcherbakov, O.P. Chikalova-Luzina, L.B. Matyushkin, M.K. Ovezov, A.M. Ershova, I.N. Trapeznikova, V.N. Petrov. Synthetic Met. 260, 116291 (2020).

[13] O.P. Chikalova-Luzina, A.N. Aleshin, I.P. Shcherbakov, V.M. Vyatkin, L.B. Matyushkin. Synthetic Met. 246, 230 (2018).

[14] L. Protesescu, S. Yakunin, M.I. Bodnarchuk, F. Krieg, R. Caputo, C.H. Hendon, M.V. Kovalenko. Nano Lett. 15, 3692 (2015).

[15] C. Santato, R. Capelli, M.A. Loi, M. Murgia, F. Cicoira, V.A.L. Roy, P. Stallinga, R. Zamboni, C. Rost, S.E. Karg, M. Muccii. Synthetic Met. 146, 329 (2004).

[16] T.J. Savenije, M.J.W. Vermeulen, M.P. de Haas, J.M. Warman. Solar Energy Mater. Solar Cells 61, 9 (2000).

[17] C.Y. Kwong, W.C.H. Choy, A.B. Djurišić, P.C. Chui, K.W. Cheng, W.K. Chan. Nanotechnology 15, 1156 (2004).

Редактор К.В. Емцев 